\title{
The effect of septoplasty on sequelae of nasal septal deviation
}

\author{
Haitham Abdul-Malik Al-Nori, Younis S. Mahdi, Ali A. Muttalib Mohammed \\ From the Department of Surgery, College of Medicine, University of Mosul. \\ Correspondence: Haitham Abdul-Malik Al-Nori. Lecturer, Department of Surgery, College of Medicine, University of Mosul, \\ Mosul, Iraq. Email: h_alnori@yahoo.com.
}

(Ann Coll Med Mosul 2013; 39 (1): 75-79).

Received: 24 ${ }^{\text {th }}$ Jul. 2012; Accepted: $2^{\text {th }}$ Apr. 2013.

\section{ABSTRACT}

Objectives: The aim of the present study is to evaluate the efficacy of septoplasty in relieving symptoms and problems attributed to septal deviation including: nasal obstruction, recurrent sinusitis, recurrent /or chronic pharyngitis, epistaxis and snoring.

Methods: This case series included eighty four patients with septal deviation severe enough to necessitate surgical intervention (severe nasal obstruction not relieved by medical treatment). The study was carried out at Al-Jumhori Teaching Hospital from July 2009 to Oct. 2010. All patients were suffering from nasal obstruction. Twenty seven patients had recurrent sinusitis, seven recurrent or chronic pharyngitis, five recurrent epistaxis, and snoring was found in four patients. The mean follow-up was six months with a range of 3-15 months.

Results: The mean age of our patients was 27.3 years with a range of 15-52 years. The study included 52 males $(61.9 \%)$ and 32 females $(38.1 \%)$ with a ratio of $1.62: 1$. Sixty eight patients $(80.9 \%)$ reported good improvement in their nasal obstruction after surgery. Improvement in recurrent sinusitis, chronic pharyngitis, epistaxis and snoring was $55.5 \%, 28.5 \%, 80 \%$ and $25 \%$ respectively.

Conclusion: We conclude that septoplasty is indicated mainly to relieve nasal obstruction resulting from moderate to severe nasal septal deviation. Other conditions which are commonly attributed to septal deviation including recurrent sinusitis, chronic pharyngitis, epistaxis and snoring are not necessarily cured by this surgery.

Keywords: Septoplasty, septal deviation.

\section{تأثير تعديل الحاجز الأنفي على عقابيل إنحراف الحاجز الأنفي}

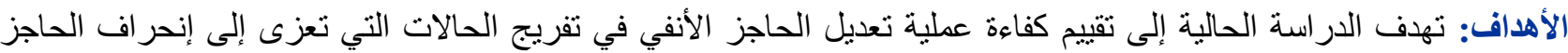

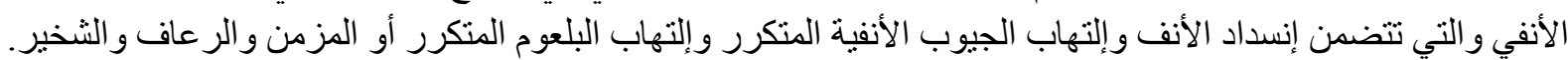

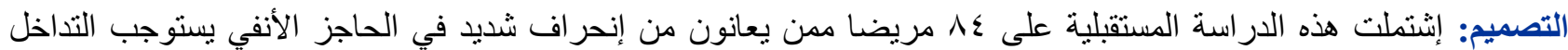

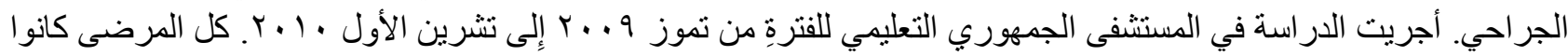

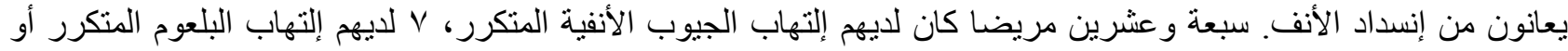

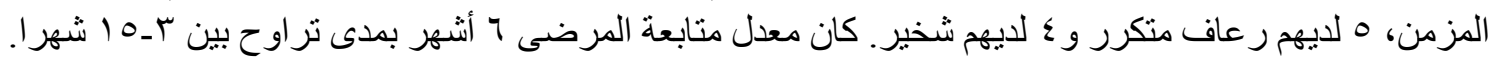

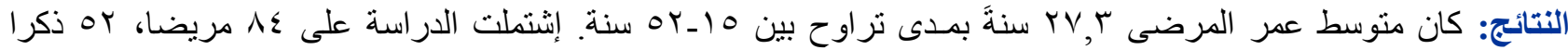

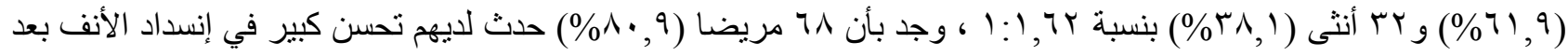

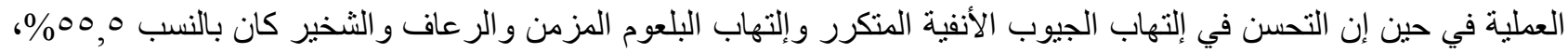

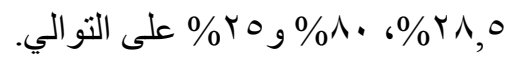

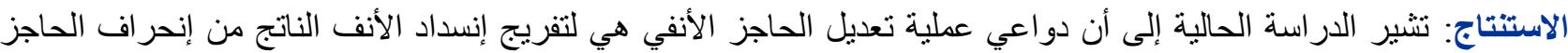

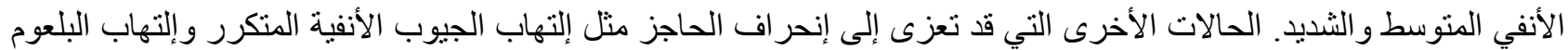
المزمن و الر عاف و الثخير لا تعالج بالضرورة لالخئ بهذه العملية. 
S eptoplasty is one of the most common ENT procedures ${ }^{(1,2)}$. Generally speaking patients with symptomatic septal deviation are advised to undergo septoplasty to relieve nasal obstruction as well as to improve other problems commonly attributed to septal deviation, namely recurrent sinusitis, recurrent / or chronic pharyngitis, epistaxis and snoring ${ }^{(3,4,5)}$. However these conditions are not related to septal deviation alone and they are multifactorial in origin; with septal deviation being one direct or indirect factor in their etiology ${ }^{(5,6)}$.

In order to understand the role of septal deviation in the aetiology of recurrent sinusitis, chronic pharyngitis, epistaxis and snoring, and to study the results of septoplasty in relieving these conditions already mentioned, this study was conducted.

\section{PATIENTS AND METHODS}

This case series study was conducted at AlJumhori Teaching Hospital for the period from October 2009 to July 2010. The study included eighty four patients (52 males $61.9 \%$ and 32 females $38.1 \%$ ) with severe nasal obstruction not responding to medical treatment, which included topical nasal steroids and antihistamine for two months. Full history was taken and medical examination was conducted with special emphasis on nasal obstruction, postnasal discharge, epistaxis, sore throat, and snoring. All patients were examined by zero degree endoscope to assess degree of septal deviation, turbinate hypertrophy, signs of sinusitis or any other pathology.

Patients with epistaxis who had bleeding from the lateral nasal wall were excluded from the study. Radiological investigations including X-ray and CT scan of the paranasal sinuses were done accordingly.

\section{Surgical Technique}

All operations were performed under general anaesthesia after infiltrating $4-6 \mathrm{ml}$ of $1 \%$ xylocain with 1:100000 adrenalin at the sub-perichondrial area of septum. Freer incision was done and separation of muco-perichondrial flaps from both sides of septum was followed by resection of a narrow basal strip (about $4 \mathrm{~cm} \times 4 \mathrm{~mm}$ ) of cartilage. Spurs were removed and scoring of concave side was done when necessary. The septum was sutured to the maxillary spine and the wound was closed with $3 / 0$ Vicryl. Nasal packs were removed after 24-48 hours. Silastic splints -if used- were removed on the $7^{\text {th }}$ postoperative day. Septoplasty was performed as an outpatient surgical procedure. Six patients $(7.1 \%)$ required overnight admission because their residence was far away from the hospital.

Patients were followed up weekly for one month and then monthly for the next five months. In every visit, the patients were asked about nasal obstruction, headache, sore throat, epistaxis and snoring. Anterior rhinoscopy and nasal endoscopy were done to assess nasal patency and the condition of the paranasal sinuses.

The mean follow up period was six months with a range of 3-15 months.

\section{RESULTS}

The study included 52 male patients $(61.9 \%)$ and 32 females $(38.1 \%)$ with a ratio of $1.62: 1$ (Fig. 1). The mean age of patients was 27.3 years with a range between 15-52 years. Figure 2 reveals that the peak age incidence was in the third decade of life.

Review of patients' data revealed that all patients had some degree of nasal obstruction; 20 patients had nasal obstruction mainly to the right (23.8\%), 9 to the left $(10.7 \%)$ and in 55 patients obstruction was bilateral $(65.4 \%)$. Twenty seven patients (32.1\%) had recurrent sinusitis, 7 patients $(8.3 \%)$ had recurrent or chronic pharyngitis, 5 patients $(5.9 \%)$ had recurrent epistaxis and snoring was encountered in 4 patients $(4.6 \%)$. Ten patients (19.2\%) had mucosal thickening in X-ray and CT scan.

Among 84 patients with nasal obstruction, 68 patients $(80.9 \%)$ were relieved completely from nasal obstruction after surgery; septi were central and airway was patent (Table 1). The remaining $19.1 \%$ reported little or no subjective improvement although the septum appeared central by examination. Fifteen out of 27 patients (55.5\%) with recurrent sinusitis showed clinical improvement after surgery. Two out of 7 patients $(28.5 \%)$ with chronic pharyngitis reported improvement, and 1 out of 4 patients (25\%) with snoring didn't snore after surgery. Epistaxis didn't recur in 4 out of 5 patients (80\%) within 6 months of septoplasty. 


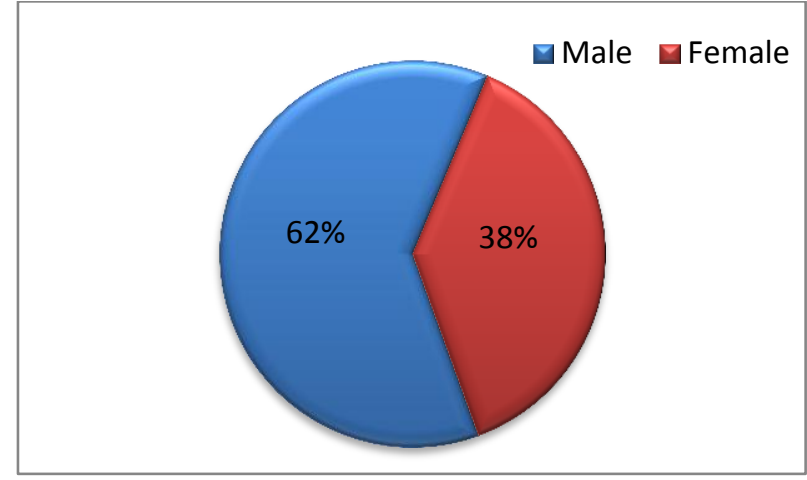

Figure 1. Sex distribution of patients.

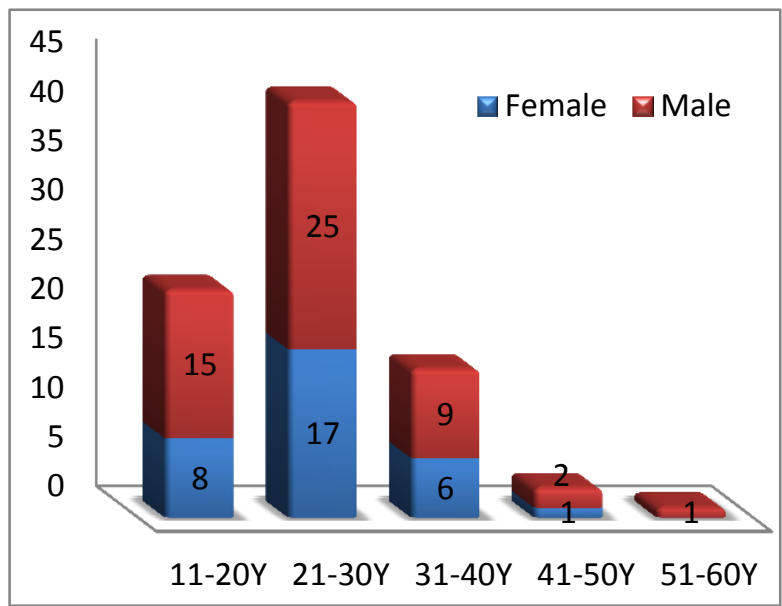

Figure 2. Age and sex distribution of patients with septal deviation.

Table 1. Incidence of sequelae in patients with nasal septal deviation and postoperative results.

\begin{tabular}{|l|c|c|c|c|}
\hline Sequelae & $\begin{array}{c}\text { Number } \\
\text { of } \\
\text { patients }\end{array}$ & $\%$ & $\begin{array}{c}\text { Number } \\
\text { of } \\
\text { patients } \\
\text { improved } \\
\text { after } \\
\text { surgery }\end{array}$ & $\%$ \\
\hline $\begin{array}{l}\text { Nasal } \\
\text { Obstruction }\end{array}$ & 84 & $100 \%$ & 68 & $80.9 \%$ \\
\hline $\begin{array}{l}\text { Recurrent } \\
\text { Sinusitis }\end{array}$ & 27 & $32.1 \%$ & 15 & $55.5 \%$ \\
\hline $\begin{array}{l}\text { Chronic } \\
\text { Pharyngitis }\end{array}$ & 7 & $8.3 \%$ & 2 & $28.5 \%$ \\
\hline Epistaxis & 5 & $5.9 \%$ & 4 & $80 \%$ \\
\hline Snoring & 4 & $4.6 \%$ & 1 & $25 \%$ \\
\hline
\end{tabular}

\section{DISCUSSION}

Our study revealed that $61.9 \%$ of patients were males and $38.1 \%$ were females, with a mean age of 27.3 years. The sex ratio is almost similar to that of Stewart MG et al who found that $64.5 \%$ of patients undergoing septoplasty were males and
$35.5 \%$ were females with a mean age of 44.7 years ${ }^{(7)}$. The difference in mean age of patients is attributed to the fact that the mentioned authors don't have maximum age for surgery, while in our study only one patient was above 50 years and all other patients were below 50 .

The improvement of nasal patency in our patients was encountered in $80.9 \%$ patients whereas $19.1 \%$ reported little or no improvement. This is slightly better than that of Dinis PB and Haider $\mathrm{H}$ who reported $77.3 \%$ improvement in nasal obstruction after septoplasty ${ }^{(8)}$. Likewise, Arunachalam PS et al ${ }^{(9)}$ found similar result $(74 \%)$. This difference may be attributed to the long period of follow-up of the mentioned authors (mean time of follow-up $=5.7$ years), as it is known that the initial improvement in nasal airway felt in the first few months after surgery is progressively deevaluated by the patient with the passing of time, particularly if other causes for nasal obstruction, such as rhinitis and rhinosinusitis also coexist ${ }^{(10)}$.

Fifteen out of 27 patients with recurrent sinusitis $(55.5 \%)$ showed clinical improvement after surgery i.e. about half of the patients. This may be explained by the conclusion of $\mathrm{Yasan} \mathrm{H}$ et al who found that mild to moderate degree of septal deviation was not a risk factor for chronic sinus disease. Only gross deviation of the septum is a risk factor for the development of chronic rhinosinusitis ${ }^{(11)}$. However Orlandi RR believed that septal deviation is associated with an increased prevalence of rhinosinusitis, although the impact of this anatomic abnormality is limited and it appears to be one of many possible factors that may lead to the development of chronic rhinosinusitis $^{(5)}$.

Aetiology of recurrent sinusitis includes anatomical abnormalities at the osteomeatal complex, cilliary dysfunction and immunological abnormalities in addition to nasal septal deviation ${ }^{(12)}$. Recurrent sinusitis needs careful assessment by endoscope and CT scan preoperatively ${ }^{(4)}$.

Our results showed that only two out of 7 $(28.5 \%)$ patients with chronic pharyngitis reported improvement after septoplasty. Aetiology of chronic pharyngitis is multifactorial and causes range from postnasal drip to smoking to gastroesophageal reflux ${ }^{(13)}$. This does not mean that severely deviated septi in patients with chronic 
sinusitis and pharyngitis should not be corrected, but it means two things:

First: because patent nasal airway is an important factor for normal physiology of sinuses and pharynx ${ }^{(14)}$ septoplasty is one step in the management of this condition that needs to be followed by antireflux therapy or further medical or surgical treatment of sinusitis according to the patient condition ${ }^{(15)}$.

Second: It must be made clear to the patient that septoplasty surgery is done primarily to relieve nasal obstruction; chronic pharyngitis and chronic sinusitis are not necessarily cured by this surgery ${ }^{(11)}$.

We found that four out of five patients with epistaxis (80\%) did not bleed within six months of septoplasty. Septoplasty is effective management of epistaxis when bleeding originates from the septum; the benefit of septoplasty with regard to epistaxis is that:

1. It cuts-off some of the rich blood supply to the septum.

2. It induces submucosal fibrosis.

3. Septal angles and spurs which are the cause of dryness and crustation are removed.

4. Another factor is that difficult points of bleeding which can't be reached due to septal deviation become easily accessible to cautery after septoplasty ${ }^{(16)}$.

Snoring is relieved by septoplasty when the obstruction is only nasal in origin (1 out of 4 patients in our study $25 \%$ ). This is the exception rather than the rule and more often snoring is multifactorial and the patient may have high arched palate, long uvula, big tongue, tonsillar hypertrophy or other causes of snoring which are not related to the nose or septum ${ }^{(17)}$. The number of patients with snoring in our study is small and it is difficult to draw conclusions, however our results go with that of Kim ST et al who found that in snorer patients with severe nasal obstruction, snoring is corrected in $19 \%$ of patients after septoplasty alone ${ }^{(18)}$. Also it was found in another study that the incidence of snoring and partial upper airway obstruction in patients with severe septal deviation is $67 \%$ and this exceeds significantly the incidence of these disturbances in population ${ }^{(19)}$.

\section{CONCLUSION}

Septoplasty is indicated mainly to relieve nasal obstruction resulting from moderate to severe nasal septal deviation. Other conditions which are commonly attributed to septal deviation including recurrent sinusitis, chronic pharyngitis, epistaxis and snoring are not necessarily cured by this surgery.

\section{REFERENCES}

1. Freer $O$. The correction of deflections of the nasal septum with a minimum of traumatism. JAMA 1902; 38: 636-42.

2. Daudia A, Alkhaddour U, Sithole J, Mortimore S. A prospective objective study of the cosmetic sequelae of nasal septal surgery. Acta Otolaryngol 2006; 126: 1201 1205

3. Siegel NS, Gliklich RE, Taghizadeh F, Chang Y. Outcomes of septoplasty. Otolaryngol Head Neck Surg 2000;122:228-32.

4. Lloid GAS, Lund VJ, Scadding GK. Computerized tomography in the preoperative evaluation of functional endoscopic sinus surgery. J Laryngol Otol 1991; 105: 181-185.

5. Orlandi RR. A systematic analysis of septal deviation associated with rhinosinusitis. Laryngoscope 2010; 120: 1687-1695.

6. Schwentner I, Dejakum K, Schmutzhard J, Deibl M, Sprinzl GM. Does nasal septal surgery improve quality of life? Acta Otolaryngol 2006;26: 752-757.

7. Stewart MG, Smith TL, Weaver EM, Witsell DL, Yueh B, Hannley MT, et al. Outcomes after nasal septoplasty: Results from the Nasal Obstruction Septoplasty Effectiveness (NOSE) study. Otolaryngol Head Neck Surg 2004; 130: 283-90.

8. Dinis $\mathrm{PB}$, Haider $H$. Septoplasty: long-term evaluation of results. Am J Otolaryngol 2002; 23: 85-90.

9. Arunachalam PS, Kitche E, Grayy J, Wilson JA. Nasal septal surgery: evaluation of symptomatic and general health outcomes. Clin. Otolaryngol. 2001; 26: 367-370.

10. Stewart MG, Smith TL, Weaver EM, Witsell DL, Yueh B, Hannley MT. Development and validation of the Nasal Obstruction Symptom Evaluation (NOSE) Scale. Otolaryngol Head Neck Surg 2004; 130: 157-163.

11. Yasan H, Dogru H, Baykal B, Doner F, Tuz M. What is the relationship between chronic sinus disease and isolated nasal septal deviation? Otolaryngol Head Neck Surg 2005;133:190-193.

12. Lund VJ, Scadding GK. Immunological aspects of chronic sinusitis. Canadian Journal of Otolaryngology $1991 ; 20: 379-381$.

13. Gleeson M, editor. Scott- Brown's Otorhinolaryngology, Head and Neck Surgery. $7^{\text {th }}$ Edition. London: Hodder Arnold; 2008. Vol 2(part 15).p.2007-2008.

14. Levison J, Mindorff CM, Chao J, Turner JAP, Sturgess JM, Stringer DA. Pathophysiology of the ciliary motility syndrome. European Journal of Respiratory disease 1983; 64 (suppl 127): 102-16.

15. Ozdek A, Cirak MY, Samim E, Bayiz U, Safak MA, Turet S. A possible role of Helicobacter pylori in chronic rhinosinusitis: a preliminary report. Laryngoscope 2003:113:679-682. 
16. Cumberworth VL, Narula AA, Bradley PJ. Prospective study of two management strategies for epistaxis. Journal of the Royal College of Surgeons of Edinburgh 1991; 36: 259- 260

17. Kao YH, Shnayder Y, Lee KC. The efficacy of anatomically based multilevel surgery for obstructive sleep apnea. Otolaryngol Head Neck Surg 2003; 129: 327- 35.
18. Kim ST, Choi JH, Jeon HG, Cha HE, Kim DY, Chung YS. Polysomnographic effects of nasal surgery for snoring and obstructive sleep apnea. Acta Otolaryngol 2004; 124: 297-300.

19. Silvoniemi P, Suonpaa J, Sipila J, Grenman R, Erkinjuntt M. Sleep disorders in patients with severe nasal obstruction due to septal deviation. Acta Otolaryngol (Stockh) 1997; 529: 199-201. 